\title{
El cementerio de los abuelos de Caspana: El espacio mortuorio local durante el dominio del Tawantinsuy ${ }^{1}$
}

Patricia Ayala R., ${ }^{2}$ Omar Reyes B., ${ }^{3}$ Mauricio Uribe R. ${ }^{4}$

\section{RESUMEN}

En este artículo se presenta un estudio del Cementerio de los Abuelos de Caspana, desde el punto de vista de las características arquitectónicas y espaciales de sus tumbas, de los individuos enterrados en ellas y del ajuar funerario asociado a los mismos. Esto, dentro los marcos de una problemática mayor, orientada a profundizar en las estrategias de apropiación o control político y simbólico del Tawantinsuyu en la región del Loa Superior, aunque esta vez desde el ámbito funerario.

\begin{abstract}
This paper presents a study about cemetery Los Abuelos de Caspana from its architectonic and spatials caracteristics of its tombs, the people died there and their funerary offerings. This work is part of a mayor problem that intents to understand the aproppiation or politic and simbolic control strategies of the Tawantinsuyu in the Upper Loa river region from the funerary contexts.
\end{abstract}

\section{Introducción}

Desde 1998 se tuvo la posibilidad de estudiar las características espaciales, arquitectónicas, osteológicas y contextuales del Cementerio de los Abuelos de Caspana, ya que con anterioridad nuestras investigaciones en la localidad dieron priori-

1 Proyectos FONDECYT 1970528 Y 1000148.

2 Email: payalerocabado@correoweb.com

3 Email: orrb@entelchile.net

4 Departamento de Antropología de la Facultad de Ciencias Sociales de la Universidad de Chile, Email: mur_cl@yahoo.com dad al estudio de sus colecciones y al trabajo de los sitios habitacionales pertenecientes al Período Intermedio Tardío y Tardío. De este modo, desde el ámbito funerario, y a partir del análisis detallado de diferentes aspectos de su cultura material, se quiso abordar el problema central del proyecto, intentando profundizar en los diferentes tipos de mecanismos puestos en marcha por el Tawantinsuyu para acceder a los recursos ofrecidos por la región del Loa Superior. ${ }^{5}$

Las primeras excavaciones realizadas en este cementerio fueron efectuadas por Le Paige (1958) quien informa acerca del hallazgo del sitio "Los Abuelos" o "Caspana 1." A mediados de la década siguiente, Núñez (1965) llevó a cabo una recolección superficial y excavó un pozo de sondeo, con la finalidad de adscribir este cementerio a un período determinado. De acuerdo a este investigador, el cementerio fue ocupado durante el período agroalfarero con evidencias Tiwanaku y preincaicas. Con posterioridad, Pollard (1982 [1970]) lo integra dentro de la segunda fase de su complejo Lasana debido a sus características "atacameñas" tardías. Aunque no se sabe la fecha exacta, el ingeniero Emil de Bruyne también excavó en este yacimiento, constituyéndose así la colección arqueológica que lleva su nombre, ubicada actualmente en el Museo Nacional de Historia Natural (Alliende 1981).

\footnotetext{
5 Otro objetivo para estudiar este sitio está relacionado con una investigación enfocada en las estrategias de interacción entre la población local y la del altiplano de Lípez (Bolivia) durante el Intermedio Tardío (Ayala 2000).
} 
Recién en 1977 se inicia una investigación sistemática en este sitio a cargo de Serracino, a la cual posteriormente se sumará Barón (1979), para realizar un estudio especialmente dedicado al análisis de los restos humanos y a la descripción de los contextos funerarios, siendo también mérito de esta investigadora la primera secuencia ocupacional para Caspana. De este modo, propone tres momentos de ocupación del cementerio de acuerdo a la distribución de las tumbas, el análisis de los cuerpos y las características de las ofrendas. El primero, correspondería a momentos tempranos del Período Formativo correspondientes a la fase Toconao del Salar de Atacama, el segundo mostraría influencias incaicas y un tercero el impacto hispano-colonial. Tampoco estarían ausentes expresiones del Período Medio san pedrino que se harían explícitas en la importante presencia del conjunto de objetos que conforman la parafernalia insuflatoria para el consumo de alucinógenos o el "complejo del rapé". No obstante, ya en la década del ochenta, a partir del análisis de la colección de Emil de Bruyne, Alliende (1981) sostiene que la influencia Tiwanaku en el caso del complejo alucinógeno de Caspana es residual, expresión de un momento final y no del período en cuestión. Además, afirma que la alfarería de la colección en ningún caso documenta una ocupación formativa del sitio, sino más bien una utilización de este cementerio durante los períodos Intermedio Tardío y Tardío, distinguiéndose la existencia de dos tradiciones culturales diferentes, una local y otra de raigambre altiplánica, antes de la llegada de los incas. ${ }^{6}$

Entre los años 1994 y 1999, nuestro equipo de investigación ha vuelto a revisar las colecciones del Cementerio de los Abuelos con el propósito de actualizar y problematizar la historia-cultural de la localidad. Específicamente, se estudiaron los materiales que integran la mencionada colección y la depositada en el Museo de Caspana, esta última correspondiente a las excavaciones de Barón y Serrracino. En un primer momento, la atención se centró en la alfarería y en el complejo alucinó-

6 No podemos dejar de mencionar las excavaciones realizadas por Bill Harris, de las cuales el único antecedente con que contamos, ya que sus resultados nunca fueron publicados, corresponde a los rótulos de varios materiales por él extraídos y depositados en el Museo de Caspana. geno, al ser los materiales más conocidos de la localidad hasta ese entonces, y porque permitían establecer relaciones cronológicas y culturales (Hermosilla y Alliende 1994 Ms, Uribe 1996 y 1997).

En estos últimos años, el sitio y sus contextos funerarios han sido objeto de diferentes tipos de análisis orientados, por un lado, a tocar el problema de su estado de conservación, y por otro, a caracterizar su arquitectura y ofrendas funerarias así como también a estudiar las osamentas humanas recuperadas en las diferentes etapas de excavación previas al inicio de nuestras investigaciones en la localidad (Ayala 1999 y 1998 Ms, Reyes 2000, Uribe 1999). A continuación presentamos los resultados obtenidos en estos últimos análisis (arquitectónico, osteológico y artefactual), los mismos que nos permitirán, en las conclusiones, introducirnos en la problemática del período de influencias incaicas en Caspana, aunque esta vez, desde el espacio mortuorio.

\section{Acerca del espacio mortuorio}

El Cementerio de los Abuelos de Caspana se localiza en la ladera noreste de la quebrada del mismo nombre, en las cercanías del Pueblo Viejo (Adán en este volumen, Figura 1). En este sector se observan varios bloques desprendidos del talud rocoso que fueron aprovechados para la construcción de estructuras funerarias de diferentes características arquitectónicas. Este sitio se encuentra dividido por un camino que sube hacia la meseta de la quebrada, cuya utilización parece remontarse a momentos prehispánicos tardíos (Varela en este volumen). En la mayoría de los casos las sepulturas están relativamente alejadas del camino, aunque en dos o tres ocasiones se encuentran prácticamente sobre él, por lo que no fue sorprendente encontrarlas completamente destruidas y sin ningún material cultural, observándose en una de ellas la presencia de restos óseos humanos expuestos en superficie.

El análisis de la distribución espacial de las 58 tumbas de este cementerio, dio como resultado la identificación de cuatro sectores localizados desde el SE al NE de la ladera (Ayala $1998 \mathrm{Ms}$ ). ${ }^{7} \mathrm{El}$ primer sector, ubicado al SE del sitio presenta escasos peñascos aprovechados para la construcción 


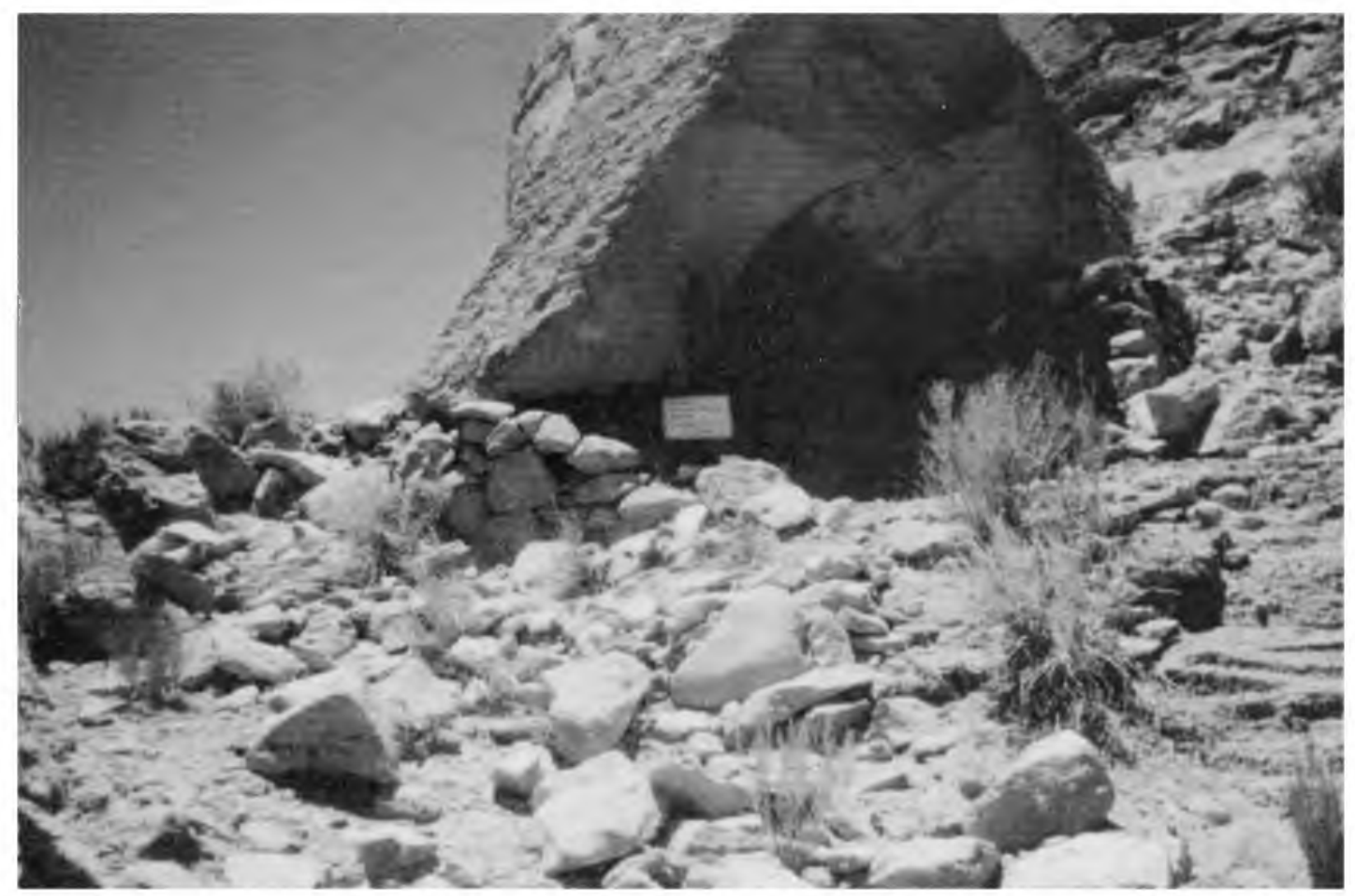

Figura 1. Tumba del tipo Bajo Bloque Rocoso

de las sepulturas y se localiza debajo del camino antes mencionado. Se trata de uno de los sectores de menor concentración de tumbas, todas del tipo Bajo Bloques Rocosos caracterizadas por estar edificadas debajo de una roca que conforma el techo y las paredes laterales de la estructura, observándose solamente la presencia de un muro frontal (con argamasa) que sella el entierro, en el cual se edificó un vano de acceso a ras de piso de forma cuadrangular o rectangular (Figura 1). En algunos casos presentan un muro de contención interior que sujeta el terreno y/o el peñasco rocoso. ${ }^{8}$ Entre las sepulturas de este sector destaca una construida bajo un peñasco de gran tamaño, frente a la cual se observa una especie de plaza o cancha, delimitada por un muro de baja altura de forma subrectangular. ${ }^{9}$

El segundo sector se localiza en la parte central del sitio, a ambos lados del camino, y se caracteriza por la presencia de un importante número de peñascos utilizados en la construcción de tumbas, constituyéndose en el área de mayor concentración de sepulturas. A diferencia de los otros sec- tores del cementerio, en éste se observan diferentes clases de tumbas, entre las cuales destacan las del tipo Adosadas a Bloques Rocosos que se caracterizan por estar construidas sobre el nivel del piso con muros levantados con hileras de piedra, simples o dobles, observándose en algunas ocasiones muros exteriores que revisten a otro interior, además de muros de contención que sujetan a los peñascos y/o al terreno. Estas edificaciones presentan vanos de acceso a ras de piso de forma rectangular o cuadrangular, además de techos construidos con piedras lajas sobre las cuales se observa fragmentería cerámica y piedrecillas, y en algunos casos una hilera de piedras que pensamos tuvo la finalidad de darle forma de torreón a ciertas estructuras. En este tipo se distinguieron

7 En algunos casos estos sectores corresponden con los descritos por Barón (1979).

8 Las tres variantes de este tipo son: Bajo Bloque Simples, Bajo Bloque Dobles B y Bajo Bloque Múltiples (Ayala 1999).

9 Por no presentar numeración, estas tumbas fueron denominadas anteponiendo la letra Y. Es posible que este sector no haya sido incluido por Barón (1979). 
cuatro variantes de las cuales se propuso analogar al patrón constructivo tipo chullpa, a dos tumbas que integran la variante denominada Adosadas Dobles $\mathrm{A}^{10}$ (Figura 2). Asimismo, se construyeron tumbas del tipo Adosadas y Bajo Bloques Rocosos, correspondientes a una situación intermedia en la cual si bien las estructuras están construidas sobre el nivel del piso, también lo están parcialmente debajo de los peñascos (Figura 3)." Al igual que en el caso anterior, en este tipo de tumbas se observó la presencia de muros de contención en algunas estructuras, apreciándose también argamasa en las paredes de la mayoría de las tumbas conservadas. Prácticamente, la totalidad de los vanos de acceso fueron construidos a ras de piso y son de forma cuadrangular o rectangular indistintamente.

Tal como señalamos anteriormente, en este espacio se observa un aprovechamiento exhaustivo de los peñascos, observándose en algunos casos seis sepulturas construidas entorno a un mismo bloque. $\mathrm{Al}$ mirar detenidamente esta área se observa que no sólo se emplearon los bloques de gran tamaño, sino también algunos de medidas más modestas que sirvieron para formar parte de las paredes o los cimientos de algunas estructuras. De acuerdo a su asociación espacial, en este sector se identificaron siete agrupaciones de tumbas que eventualmente podrían relacionarse arquitectónica y contextualmente. De estas agrupaciones destaca el Conjunto 3 conformado por seis tumbas construidas alrededor de un espacio localizado en un sector relativamente plano que pudo hacer las veces de "plaza". Algunas de las sepulturas que lo rodean se construyeron orientadas a este espacio, por lo cual ésta podría considerarse el área central de este sector del cementerio. También destaca el Conjunto 4 por la presencia de las sepulturas 3637 que se proponen analogar al patrón constructivo tipo chullpa debido a sus características constructivas (Aldunate y Castro 1981, Ayala 2000 a y $1998 \mathrm{Ms}$ ). En este mismo conjunto se encuentran las tumbas 21-22 que tienen cierta similitud con las anteriores, aunque no alcanzan a independizarse completamente del bloque rocoso aprovechado para su construcción. En este sector llama la atención la gran cantidad de deshechos de malaquita o walca, diseminados fundamentalmente al exterior de las sepulturas, de manera similar y quizá más densa de lo que se aprecia en la "plaza" de la Colina Sur del Pukara de Turi (Aldunate 1993, Castro et al. 1993). Junto con esto, también se observa fragmentería cerámica y restos óseos humanos en superficie, los que a diferencia de la malaquita que fue depositada dentro de una ritualidad dirigida hacia los muertos, son el resultado de la acción antrópica que ha afectado al sitio.

El tercer sector se ubica más al NE del sitio, sobre el camino, caracterizándose por presentar escasos bloques rocosos dispersos y distantes entre sí, conformando uno de los sectores de menor concentración de tumbas del cementerio. Al igual que en el primer sector, se construyeron exclusivamente sepulturas del tipo Bajo Bloques Rocosos, estableciéndose de este modo una distribución diferencial de acuerdo al tipo de tumbas en el cementerio. ${ }^{12}$ Se maneja la hipótesis de trabajo de que en este sector, se encuentran las sepulturas enumeradas por Barón de la 1 a la 11, debido a que su descripción de la sepultura $\mathrm{N}^{\circ} 10$ podría corresponder con una de las tumbas registradas en este sector (X5). Asumiendo las limitaciones de esta inferencia, consideramos la posibilidad de que la Tumba $N^{\circ} 7$, donde se observa la mayor cantidad de cerámica asociada a momentos de influencia incaica, se encuentre en este sector, teniendo en cuenta además que dos sepulturas encontradas en las cercanías de Cerro Verde, presentan características arquitectónicas similares al ser construidas aprovechando oquedades rocosas.

El cuarto sector se ubica en las márgenes del Pueblo Viejo, en el antiguo patio del caspaneño Julián Colamar, específicamente al NE del sitio. De acuerdo a lo observado por Barón en este sector se encontró una gran concentración de entierros subterráneos sin ningún tipo de señalización ni elemento constructivo, los cuales fueron individualizados como Tumba $\mathrm{N}^{\circ} 60$. Sus características contextuales permiten afirmar que corresponde a un cementerio posthispánico, en el cual se registraron cuerpos en posición extendida,

10 Estas tumbas se parecen a una variedad del tipo de chullpas Dobles de Talikuna (Ayala 2000 a).

11 Este tipo tiene dos variantes: Adosadas/Bajo Bloque Simples y Adosadas/Bajo Bloque Dobles B.

12 Por no estar numeradas estas tumbas se denominaron anteponiendo la letra $X$. 


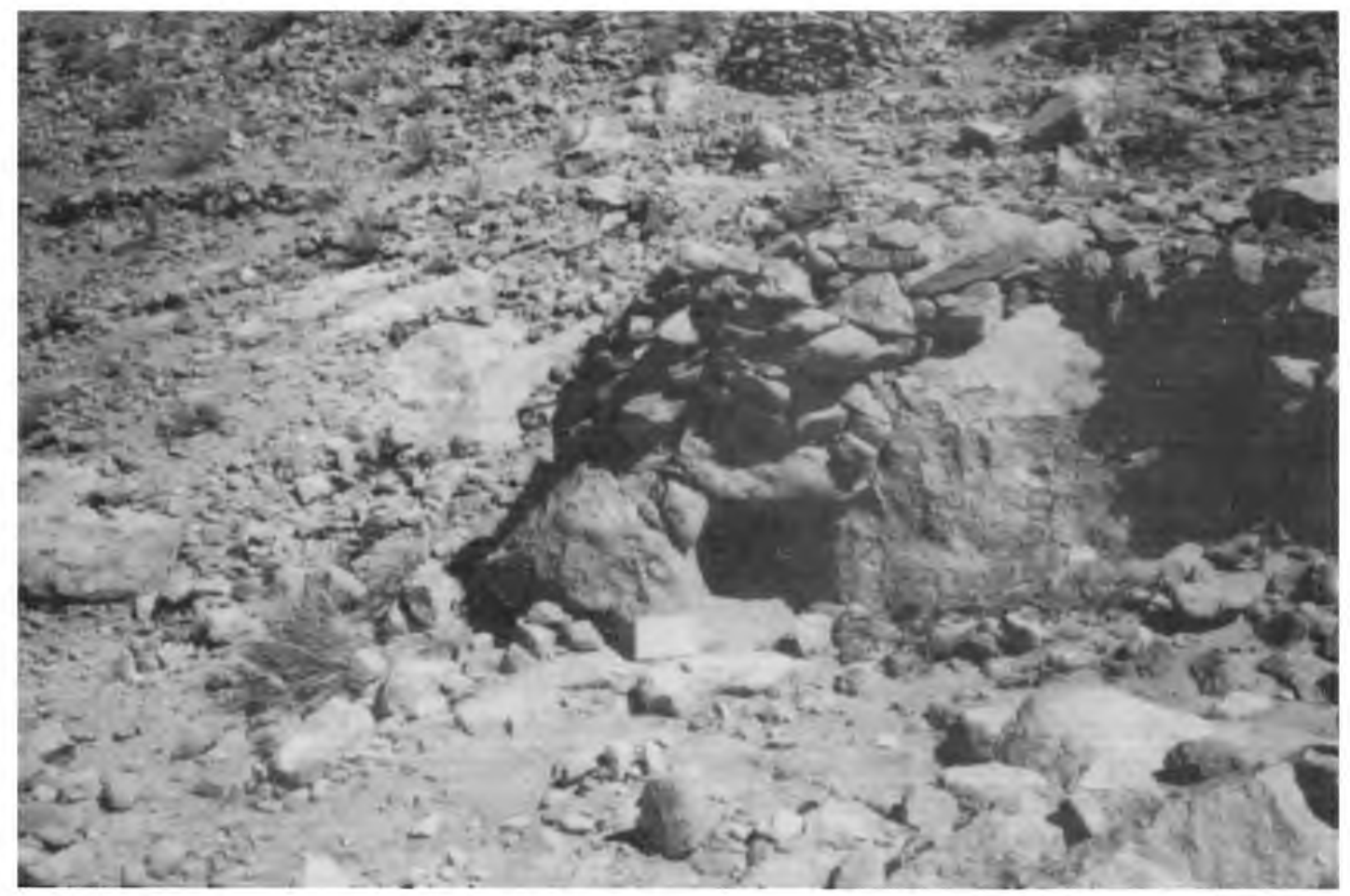

Figura 2. Tumba del tipo Adosada a Bloque Rocoso

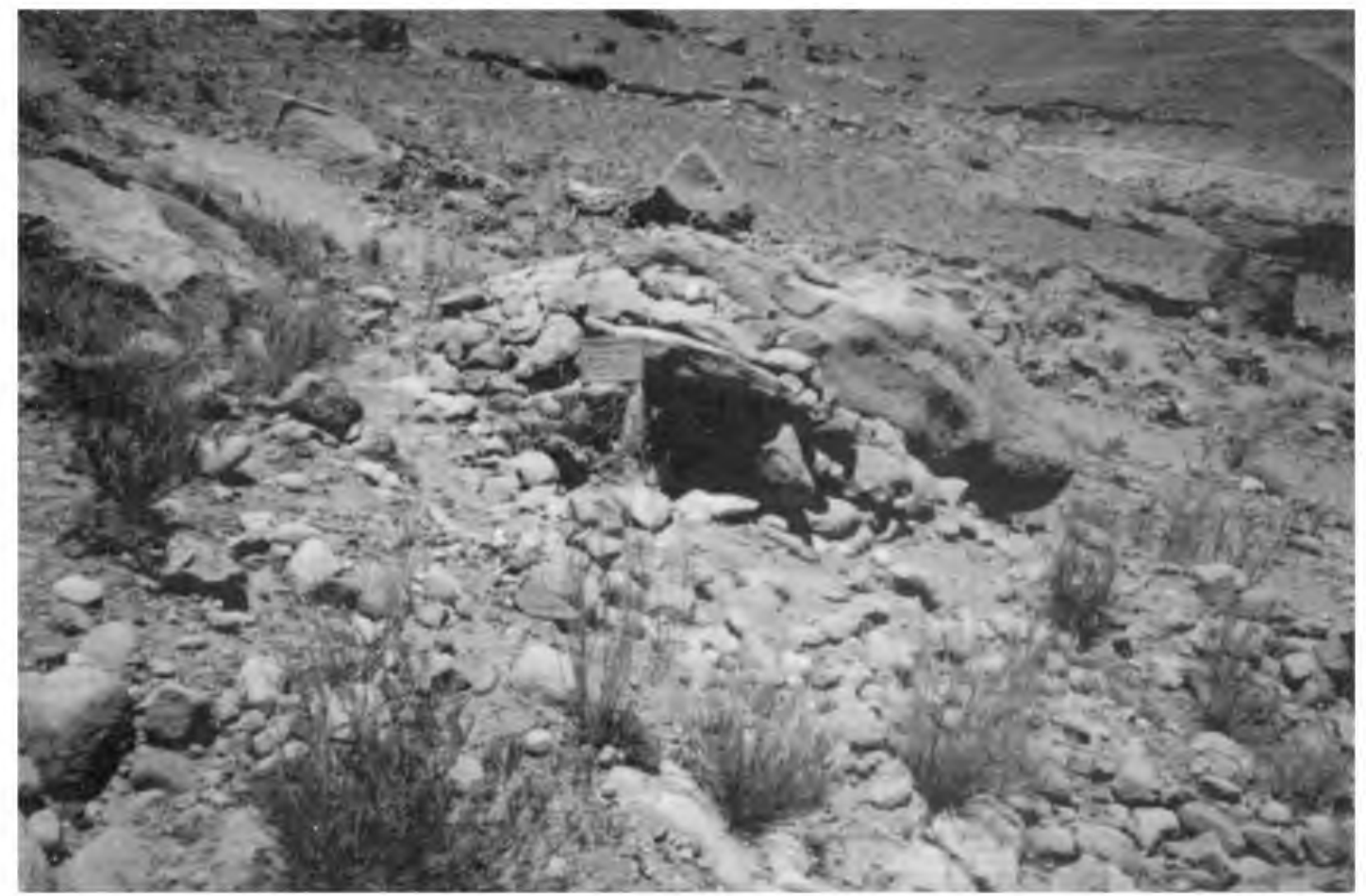

Figura 3. Tumba del tipo Adosada y Bajo Bloque Rocoso 
a diferencia de la posición flectada de los individuos inhumados en los otros sectores, junto a ofrendas de raigambre hispana. Lamentablemente, en la actualidad ya no se observa este sector debido a la construcción de viviendas sobre el mismo. Sin embargo, hay que destacar el cambio en la ocupación del espacio del cementerio ya que este grupo de tumbas, se encuentra relativamente alejado del resto y a una altura más baja de la ladera.

Respecto a las orientaciones orográficas de los vanos de acceso conservados en las tumbas de este cementerio, se observa que el $14 \%$ y el $10 \%$ de ellas se construyeron con sus aperturas mirando hacia los cerros de Aiquina y Cablor-Chita, respectivamente. Sin embargo, un significativo número de sepulturas están orientadas a la ladera misma del cementerio, alcanzando el $14 \%$ de representatividad, seguido finalmente por un grupo de tumbas dirigidas hacia un sector de lomajes cercanos al "Pueblo Nuevo" de Caspana, obteniendo un porcentaje del $7 \%$. El resto de las estructuras no conservaban su vano de acceso, razón por la cual el $54 \%$ restante corresponde a vanos no observados. En cuanto a las orientaciones cardinales, se observa que el $25,31 \%$ y $24,56 \%$ de las tumbas miran al NO y SE respectivamente, hacia donde se localizan los cerros mencionados. Seguidamente, se tiene que el $7 \%$ de ellas se dirigen al NE mirando al resto de las sepulturas del sitio, para concluir con el $3,5 \%$ y el $1,75 \%$ de los vanos que se orientan al SO y O del cementerio. ${ }^{13}$

Teniendo en cuenta los distintos tipos de tumbas y su distribución en el cementerio, se plantean diferentes momentos de ocupación a partir del Período Intermedio Tardío. El primero se asociaría a sepulturas Bajo Bloques Rocosos, dispersas en la ladera de la quebrada de Caspana, de manera similar a lo observado en el sector de enterratorios dispuestos en la parte alta del sitio Talikuna, a metros del sector residencial. Esta primera etapa de ocupación estaría evidenciada en el sector SE del sitio, caracterizado por corresponder a uno de los espacios de menor concentración de tumbas, vinculados a un posible asentamiento localizado debajo del Pueblo Viejo (Adán en este volumen). Un segundo momento de ocupación pudo estar relacionado con la construcción de las sepulturas "intermedias", cuando las estructuras funerarias comenzaron a elevarse y a construirse Adosadas aunque Bajo Bloques Rocosos. Posteriormente, también en el sector de mayor concentración de tumbas, se construyeron sepulturas sobre el nivel del piso Adosadas a los Bloques Rocosos, de características muy diferentes a las del resto del río Loa y más similares a las tumbas construidas en el altiplano, por lo que podría pensarse en una etapa en que las relaciones con esta región tomaron un matiz distinto al que ya tenían anteriormente. ${ }^{14}$ Esto se vería apoyado también por la presencia de tumbas adscritas al patrón constructivo tipo chullpa, que representarían un momento crucial en la ocupación de este cementerio posiblemente relacionado con un cambio en el tipo de relaciones establecidas entre los pobladores prehispánicos de Caspana y los del altiplano de Lípez en momentos más bien tardíos del Intermedio Tardío. Situación que podría ser entendida en términos de una intensificación de los lazos entre ambas regiones o quizá estar relacionada con el entierro de señores altiplánicos importantes. ${ }^{15}$ También es probable que la construcción de chullpas en este cementerio haya sido gatillada por la presencia incaica en la localidad, en favor de exaltar los vínculos con las entidades altiplánicas como parte de una estrategia utilizada por los locales para "igualarse" a dichos grupos ante los ojos del Inca.

Junto con esto, otras tumbas que hipotéticamente podrían asociarse al Período Tardío, son aquellas que presentan un muro exterior que "reviste" otro interior, pudiendo corresponder el muro interno a una estructura previamente utilizada por la población local, y el externo a un tratamiento dado en momentos posteriores vinculados a la presencia inca, de manera similar a lo observado en Sillustani

13 El 36,84\% restante, corresponde a sepulturas cuyos vanos no fueron identificados.

14 Los vínculos con el altiplano son muy evidentes, sobretodo considerando que las tumbas Bajo Bloques Rocosos integran la "configuración altiplánica" de Toconce (Castro et al. 1984).

15 Las tumbas analogadas al patrón chullpa comparten un mismo espacio dentro el cementerio, lo que podría interpretarse como una utilización selectiva del espacio quizá asociada al entierro de personajes de mayor estatus. 
(Puno, Perú), donde varias chullpas edificadas durante el Intermedio Tardío fueron ocupadas en tiempos del Inca después de recubrir las estructuras previas con muros construidos al mejor estilo cusqueño (Tschopick 1946). Sugerencia que deberá ser puesta a prueba cuando se cuente con mayor información acerca de los contextos de estas tumbas.

En cualquier caso, parece que durante el período incaico continuaron ocupándose aquellas tumbas Bajo Bloque Rocoso construidas desde momentos tempranos del Intermedio Tardío, junto con otras edificadas aprovechando oquedades rocosas como las observadas en las cercanías de Cerro Verde. Esto debido a que sostenemos que la Tumba $\mathrm{N}^{\circ} 7$ que presenta la mayor cantidad de alfarería de filiación incaica del sitio, se encuentra en el tercer sector del cementerio según lo podemos inferir de las descripciones de Barón, en ausencia de la numeración de las sepulturas de este sector. Recordemos que en tiempos del Tawantinsuyu fueron muy populares las sepulturas en oquedades rocosas (Eaton 1990[1919]), asociadas al culto de los antepasados, el cual considera que la pacarina o lugar de origen puede ser una fuente, momia o una gruta, destacando estas últimas por su parecido con las sepulturas en cuestión.

Debajo de este tercer sector, se localiza el cuarto sector individualizado por Barón como Tumba $\mathrm{N}^{\circ}$ 60. Como se verá más adelante, en el análisis de sus contextos funerarios, anteriormente asignado a tiempos indígena-coloniales, se identificaron claros contextos alfareros incanizados, lo que no es de extrañar si consideramos que todos lo contextos funerarios de este sector fueron englobados dentro un mismo conjunto. Lo anterior, sin duda, provocó confusión a la hora de determinar el momento de ocupación del mismo, pues evidentemente debió ocuparse en momentos coloniales, pero al parecer sobre una previa ocupación durante el Tardío.

En suma, a pesar de las limitaciones de nuestras inferencias debido a los vacíos de información que enfrentamos, nos atrevemos a plantear que durante el Período Tardío, el Cementerio de los Abuelos fue mayormente ocupado en su lado noreste, más arriba (tercer sector) o por debajo de la ladera (cuarto sector), pudiendo corresponder cada sector a un momento de la ocupación incaica, de manera similar a lo que se observa en los sitios habitacionales de la localidad, relacionándose el tercer sector con una primera etapa de influencias incaicas (asociada a cerámica local tradicional con formas incas de la Tumba $\mathrm{N}^{\circ}$ 7) y el cuarto con una segunda etapa de presencia del Tawantinsuyu (asociada a cerámica local, pero "pasta con mica"). Esto apoyaría la idea de que el Estado incaico dentro de sus estrategias de apropiación o control político y simbólico, ocupaba espacios distintos al de los locales, en este caso, bordeando su núcleo mortuorio. Pero además se notan intentos de lo contrario, si consideramos la hipótesis de que algunas de las tumbas del tipo Adosadas a Bloques Rocosos que presentan muros exteriores que revisten otros interiores se asocian a la influencia incaica, podría plantearse que es en este sector de mayor aglomeración de tumbas donde lo inca llega en algún momento a "convivir" con lo local. Esta sería la máxima expresión del éxito logrado por su estrategia de dominación, manifestada por el manejo del espacio mortuorio. Sin embargo, el nivel de información con que contamos nos obliga a ser cautelosos al respecto.

\section{Acerca de los cuerpos}

Respecto a los cuerpos depositados ${ }^{16}$ en el Cementerio de los Abuelos, a continuación se presentan los resultados del análisis antropológico físico de los restos humanos recuperados en las excavaciones arqueológicas realizadas en este sitio (Barón 1979), como parte fundamental para tratar la problemática incaica en la localidad de Caspana.

Si bien anteriormente se realizó un análisis a la mayor parte de las osamentas exhumadas (Barón 1979), éste no pasó de identificar individuos a veces por sexo, a veces por edad y con alguna referencia sobre condiciones patológicas, pero de manera muy aislada. Los nuevos avances y métodos del análisis osteológico, permiten precisar edad y sexo, así como también las condiciones de salud reflejadas en un individuo y en un conjunto de individuos. Esto permite inferir modos de vida conjugando la relación hombre-cultura y medioam-

16 No parecen haber sido enterrados. 
biente, perspectiva bajo la cual se abordó la colección de las tumbas colectivas del cementerio de Caspana.

De la serie de osamentas provenientes de las tumbas excavadas y depositadas en el Museo de Caspana, fue posible analizar la mitad de la muestra total allí reunida. Las condiciones de preservación y rotulado permitieron el análisis de 33 individuos, casi todos incompletos, erosionados y en un muy frágil estado de conservación. Sin embargo, fue posible registrar y catalogar a cada uno de ellos, además de interpretar modos de vida relacionando la actividad económica, alimentación, paleopatologías y trabajos efectuados por esta población (Reyes 2000), complementando así el estudio de Barón (1979).

En cuanto al material y métodos considerados en este estudio, los 33 individuos provienen de diferentes tumbas colectivas correspondientes a distintos momentos de ocupación del cementerio. Tres de estas tumbas colectivas presentan elementos culturales (alfareros principalmente), claramente asignables al Período Tardío de influencia incaica en la región. La Tumba $\mathrm{N}^{\circ} 7$ con 11 individuos, la Tumba $\mathrm{N}^{\circ} 60$ con, a lo menos, 21 individuos y la tumba $\mathrm{N}^{\circ} 61$ con una cantidad indeterminada de personas (quizás sobre 30), representan dicho período. El estado en que se encontraron las osamentas permitió el registro de sólo siete individuos de la Tumba $\mathrm{N}^{\circ} 7$ y de 10 individuos de la Tumba $\mathrm{N}^{\circ} 61$, que constituyen la muestra analizada para este trabajo en particular $(n=17)$. De la tumba $N^{\circ} 60$ sólo se conoce el contexto fúnebre y datos bioantropológicos muy aislados que no permiten mayor análisis.

El registro de cada uno de los individuos fue llevado a una ficha tipo de examen macroscópico en el cual además, se vierten indicadores tales como: rasgos discretos del cráneo (Brooks et al. 1990, Napoli y Birkby 1990) y postcráneo (Gilbert y Gill 1990); fases etarias definidas por la obliteración de las suturas ectocraneales (Meindl y Lovejoy 1985), desarrollo y desgaste de la dentición (Hillson 1996), cambios en el borde esternal de la cuarta costilla (Loth e Iscan 1989), cambios morfológicos de la superficie auricular del ilión y de la sínfisis púbica (Lovejoy et al. 1985), correlación entre edad cronológica estimada y largo máximo de diáfisis (subadultos) y cierre de los puntos de osificación secundarios postcraneanos (Brothwell 1987, Shipman et al. 1985, Ubelaker 1996). Para definir las categorías sexuales de los individuos, sólo se usó como criterio el examen morfoscópico en torno a la estructura ósea, el cual contempló en orden de importancia: cintura pélvica, cráneo y mandíbula, y la composición general del esqueleto postcraneal. Los parámetros para determinar grado de abrasión (Hillson 1996, Quevedo y Urquieta 1975), cantidad de tártaro dental (Marti et al. 1994), grado de retracción alveolar, se conjugaron en un odontograma haciendo más coherente la información obtenida referente a la salud bucal. El resto de condiciones patológicas del cráneo y postcráneo es abordado según la nomenclatura tradicional dependiendo de las características del caso (p.e. Aufderheide y Rodríguez-Martín 1998, Kennedy 1989, Ortner y Putschar 1981).

Los resultados del estudio realizado, nos permiten decir que de un total de 17 individuos, sólo se pudo asignar su categoría sexual a 12 , en tanto que otros cinco individuos fueron declarados indeterminados por la escasez de material. En cuanto a las características etarias de la muestra analizada, en ella se observa todas las edades representadas, considerando los siguientes rangos etarios: infantes (0-4 años), niños (5-9 y 10-14 años), adolescentes (15-19 años), adulto joven (2024 años), adulto maduro (25-29, 30-34, 35-39/4449 años) y adulto senil (50 y más).

Del análisis paleopatológico efectuado a los individuos de estas dos tumbas colectivas, podemos concluir que las zonas del esqueleto que más estuvieron afectadas por condiciones patológicas y estresantes fueron la cavidad bucal y la columna vertebral. Los tipos de afecciones más comunes que se identificaron en el resto del esqueleto postcraneal corresponden a cuadros osteoporóticos, carenciales, infecciosos, osteoartríticos, entesopatías y una pequeña incidencia de traumas evidentes pero no mortales.

Las afecciones observadas en la cavidad bucal de los individuos, se registran desde temprana edad. Comprenden enfermedades periodontales (infecciones, abscesos, retracción de la gingiva, expulsión del diente de su alvéolo), la pérdida en vida 
de piezas dentales (reabsorción de los alvéolos) y la condición que presentaban los dientes (grado de desgaste dental, caries, tártaro dental). La hipoplasia del esmalte dental no pudo ser diagnosticada. Lo sesgado de la muestra, ausencia de piezas dentales, el desgaste que presentaban y el tártaro que las cubría, dificultaba éste diagnóstico. Es así como la pérdida de piezas dentales comienza a partir de la segunda década de vida, llegando a los 50 años con un promedio que oscila alrededor de 20 piezas perdidas para ambos sexos. A esto se suma el desgaste dental desde la niñez hasta pasado los 25 años, en donde aumenta con la exposición de la dentina, conformando varias manchas alrededor del esmalte en su cara oclusal, para luego llegar al aislamiento del diente por pérdida de esmalte, dentina y por la perforación de la cámara pulpar. Como este proceso es permanente a lo largo de la vida del individuo, pasado los 40 años las piezas que sobreviven se ven expuestas a condiciones de desgaste mayor llegando inclusive a la gangrena pulpar y a la patología apical de las tablas internas y externas del hueso alveolar. Por su parte, el desgaste dental se explica por la consecuencia de tres factores, por un lado, la ingesta de una dieta eminentemente agrícola, compuesta por alimentos menos procesados como vegetales duros (p.e. gramíneas) o crudos, los que por su textura y abrasividad --potenciadas por cenizas, arenillas o microgranos de pedregullo adosados en su preparación (p.e. molienda)--, desgastan por abrasión permanentemente la corona (esmalte, dentina y pulpa), es decir, microdesgaste acumulativo. ${ }^{17} \mathrm{El}$ otro factor obedece a la atrición provocada por el contacto normal de diente con diente principalmente en la cara oclusal o bien, por maloclusión de la arcada dental. Por último, el tercer factor se relaciona con que la boca fue utilizada como herramienta de trabajo o tercera mano, así es posible por ejemplo raer o curtir cueros y sujetar determinados elementos, los que van originando surcos y otras marcas

17 Un registro semejante se observó en la salud oral de los individuos del cementerio Coyo 3 en San Pedro de Atacama, donde la "dieta agrícola" no se relaciona directamente con los grados de abrasión detectados (Costa-Junqueira y Llagostera 1994). reconocibles (cestería, cordelería, etc.). Una actividad así, se suma al constante proceso de desgaste de las piezas. Agregamos además, que fue observado en gran cantidad de casos el notable desarrollo de la tuberosidad zigomaxilar, que por ser una tuberosidad funcional que responde al estrés mecánico al que se somete la boca, se convierte en un elemento diagnóstico junto a la morfología muscular maxilofacial.

Contribuye a esta salud deficiente, la presencia de caries dentales principalmente en los molares. Agregamos la presencia del tártaro dental que oscila de moderado (cubre hasta dos tercios de la superficie coronaria) desde la infancia hasta los primeros veinte años, a abundante (cubre la totalidad de la pieza dental). La acumulación de alimentos vegetales procesados (dieta agrícola con productos farináceos) y la falta de limpieza, causa la intrusión en las fisuras y los espacios interdentales de material residual, gatillando la formación de placa bacteriana que contribuye con la desmineralización del diente, la producción de caries, el compromiso de la pieza, la inflamación y retracción de la gingiva y la pérdida de la pieza en los casos más severos.

Las patologías de la columna vertebral abarcan el segundo factor de importancia en las afecciones de esta población, afectando por igual tanto a hombres como mujeres. En este sentido, la observación etnográfica entrega interesante información al apreciarse que los pobladores de Caspana cargan grandes fardos de pasto sobre las espaldas llevándolos a través de grandes distancias, así como también invierten gran esfuerzo en la construcción de viviendas, en las faenas pastoriles, agrícolas (construcción y mantenimiento de extensos andenes) y mineras, ambas con notables evidencias arqueológicas en los sitios estudiados, que imponen una casi permanente actividad con posturas que afectan notablemente la parte baja de la espalda (sobre todo la zona lumbar). Por otro lado, el grado de desarrollo de porosidades, anillos marginales, osteofitos y lipping de algunos cuerpos vertebrales junto a edades no tan avanzadas (segunda y tercera décadas), contribuyen a ver este cuadro patológico como producto del estrés físico antes que un proceso degenerativo de las articulaciones. Es notable también la detección de nódulos de Schmorl o herniación de los discos 
intervertebrales en las zonas cervicales, dorsales y lumbares. La tonicidad muscular, presente en casi todos los esqueletos adultos, especialmente en la cintura escapular, también apoya esta afirmación. Con el avance del tiempo, el normal proceso de desgaste de los tejidos óseos se confunde con los efectos producidos por las presiones físicas de décadas de trabajo y los permanentes microtraumas que actuaron sobre la masa ósea, tornándose en un cuadro osteoartrítico difuso. Afortunadamente, la muestra de individuos adultos jóvenes y maduros nos permite observar y diagnosticar los síntomas de estos procesos patológicos. La porosidad de los huesos, reflejada en diversas partes del cuerpo, afecta sobre todo a las mujeres adulto maduras y a los adultos seniles en general. Esto se atribuye principalmente a tres condiciones: procesos infecciosos (periostitis), carencias nutricionales y osteoporosis relacionada con la edad y con el segundo factor mencionado. Notablemente, los cuadros osteoartríticos y los traumas son bajos tanto en hombres como en mujeres. Lesiones, desgarros e impedimentos para efectuar movilidad no existen. La producción osteofítica en las epífisis de los huesos postcraneales es mínima y la anquilosis no se advierte. La columna vertebral es la única gran excepción de este estado.

Los traumas por otro lado, son bastante bajos, pudiendo decirse que los índices de accidentes o violencia no son relevantes para la sobrevida del grupo ni de los individuos. Las entesopatías (hipertrofia de los músculos principales) detectadas nos hablan del sobresfuerzo de hombres y mujeres en las labores agrícolas, mineras y pastoriles, donde las zonas más afectadas corresponden a las extremidades superiores, cintura escapular y extremidades inferiores.

Lamentablemente, el registro antropométrico es escaso. La gran mayoría de los esqueletos de estas tumbas colectivas estaban fragmentados e incompletos como para establecer estaturas y distancias entre puntos craneométricos. Sólo tres individuos pudieron ser medidos, una mujer adulta (Tumba $\mathrm{N}^{\circ}$ 7, Ind.3) de $152 \pm 3,8 \mathrm{~cm}$, un hombre adulto (Tumba $\mathrm{N}^{\circ} 7$, Ind.2) de $167 \pm 3 \mathrm{~cm}$ y un hombre adulto (Tumba $\mathrm{N}^{\circ}$ 61, Ind.Art.1) de $170 \pm 3 \mathrm{~cm}$ de altura. Si bien, la muestra es débil en cuanto a parámetros demográficos, cabe seña- lar que la media de estatura para hombres y mujeres de las otras tumbas colectivas sin elementos culturales asignables a influencias incaicas es menor, $163 \pm 3,5 \mathrm{~cm}$ y $151 \pm 3,5 \mathrm{~cm}$ de estatura respectivamente. La respuesta puede estar en el pequeño tamaño de la muestra, la normal variación individual dentro de una población o bien, a cambios en cuanto al acceso alimenticio de una población con respecto a otra.

Con todo, la población muestreada de las tumbas colectivas $\mathrm{N}^{\circ} 7$ y $\mathrm{N}^{\circ} 61$, no refleja un estado de salud distinto al de los otros individuos de las tumbas colectivas sin elementos culturales asignables a influencias incaicas. En general, se observan patologías producidas mayormente por dieta y estrés físico ante actividades agrícolas, mineras y pastoriles. La mortandad abarca todos las categorías etarias, pero con mayor énfasis en la etapa adulto maduro (sobre 25-50 años). Podemos decir que la esperanza de vida es alta, alcanzado la mayoría de los individuos la etapa adulta, sin embargo, al no contar con toda la muestra y al no estar ésta en buenas condiciones de preservación, se hace difícil extrapolar más datos.

\section{Acerca de las ofrendas}

Respecto a las ofrendas con que se sepultaron a los difuntos en el Cementerio de los Abuelos, sin duda la alfarería constituye uno de los artefactos preferidos a la hora de conformar el ajuar funerario que acompañaba a los muertos durante los períodos Intermedio Tardío, Tardío e Indígena-Colonial, mostrando a través de la cerámica el contexto cultural en el cual se desenvolvió el individuo enterrado. De este modo, dichos materiales confirman la presencia de complejos cerámicos propios de la vertiente occidental circumpuneña (desierto de Atacama), del altiplano meridional de Bolivia (Lípez) y del Noroeste argentino (puna atacameña) (Uribe y Carrasco en este volumen). Sin duda, el primero de ellos corresponde a la industria local o de la Tradición del Desierto, por supuesto mayoritaria, donde destacan los platos o pucos Dupont, Aiquina y aquellos revestidos rojos. También, aunque más esporádicamente, aparecen los cuencos, cántaros y ollas alisados y/o revestidos rojos (en el caso de los dos primeros), en su mayoría denominados Turi. ${ }^{18}$ Por su parte, una tradición altiplánica post-Tiwanaku se encuen- 

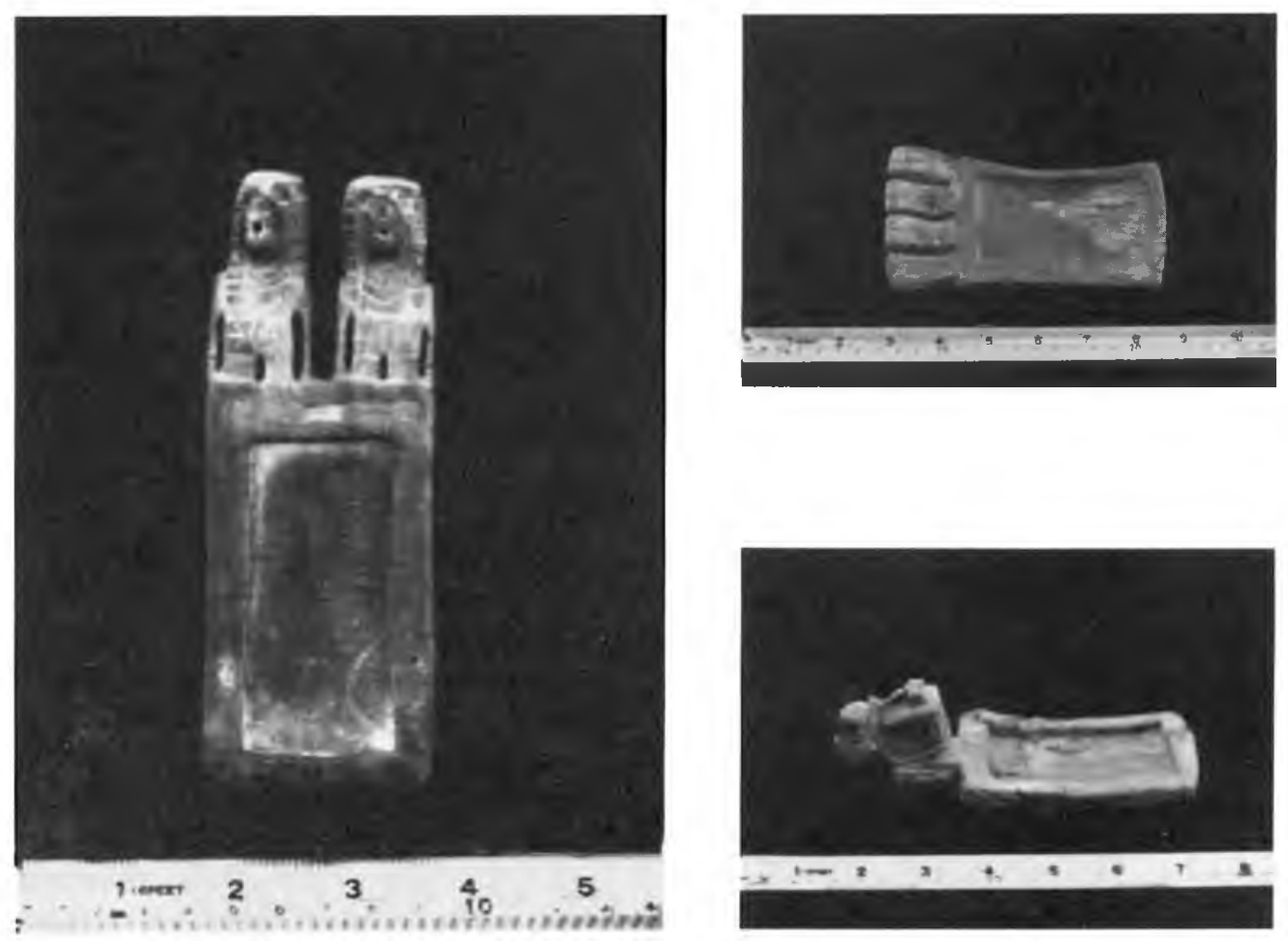

Figura 4. Tabletas del complejo alucinógeno

tra representada por los platos y algunos pequeños cántaros decorados del tipo Hedionda Negro sobre Ante originario del altiplano de Lípez (Nielsen 1998). Pero además, comprende la manifestación de una producción que reproduce su morfología e iconografía en vasijas elaboradas con materias primas locales. Del mismo modo, del noroeste argentino se encuentran platos y cántaros de estilo Yavi del Intermedio Tardío, así como un híbrido que denominamos Yavi-La Paya que parece ser producto de la expansión del Tawantinsuyu, cuyas pastas en todos los casos delatan indudablemente un origen foráneo. En este sentido, lo incaico también se manifiesta en una industria local donde, además de generar cambios en las pastas, se producen las escudillas con rasgos ornitomorfos, los aríbalos, las ollas con pe-

18 Fue en el Pukara de Turi donde se definieron estos tipos (Varela et al. 1993). destal y los jarros, en general revestidos rojos, pulidos y sin decoración. Con todo, los jarros se popularizan en tiempos de influencia incaica, seguramente porque antes no existían en el repertorio local, convirtiéndose en el elemento más diagnóstico de su presencia. De hecho, los jarros perduran como ofrendas en las épocas coloniales y etnográficas, junto con algunos platos y ollas, al mismo tiempo que producto de dicho proceso se integran totalmente las "pastas con mica" en la industria alfarera hasta la actualidad (Uribe 1999). Por último, otras vasijas del Período Tardío han sido difíciles de determinar en cuanto a su origen, mientras que ciertos ejemplares son absolutamente minoritarios como, por ejemplo, el tipo Saxamar adjudicado a poblaciones altiplánicas incanizadas (Pacajes).

Por otro lado, se pudo constatar la presencia del complejo alucinógeno de Caspana, constituido por tabletas, tubos, espinas de cactus, cajas, espátulas y tablillas, probablemente asociados a bolsas de 
cuero y conchas de almeja u ostión. Las tabletas son todas de madera, circulares, rectangulares, ovales y decoradas con apéndices escultóricos y/ o incrustaciones en el reborde (Figura 4). Los tubos son de hueso de ave y madera, en estos últimos también se reconocen adornos escultóricos y hasta aplicaciones donde destacamos la imagen del "sacrificador". Del mismo modo, las cajas son de hueso y madera, cilíndricas, con cintura y rectangulares, algunas de las cuales se encuentran decoradas con diseños geométricos o antropomorfos (cilíndricas) y otras conservan una tapa de cuero puesto para guardar la sustancia psicoactiva. Lo mismo ocurre en términos de materias primas con las espátulas ya que también son de hueso y madera, estando constituidas por una cucharita, una punta en el extremo opuesto para raspar, por lo general presentan un par de protúberos en el mango, están decoradas con incisos que generan diversos diseños, a veces pirograbados y en algunos casos con motivos antropomorfos. Finalmente, las tablillas son trozos de madera rectangulares que funcionaban como estuches para portar coloridas plumas que se envolvían con una tela de cuero, cocida a la tablilla por medio de agujeros en las orillas de ésta.

El estudio de los elementos que componen el complejo alucinógeno del cementerio también confirma que las tabletas corresponden al Período Intermedio Tardío relacionado con el noroeste argentino, más exactamente con la puna de Jujuy. Lo anterior se refuerza por la presencia de la cerámica Yavi en sus distintos estilos decorativos asociados a dicho período y calabazas pirograbadas con motivos derivados de la cerámica La Paya (p.e. aves) y Santa María-Belén (p.e. serpiente bicéfala) (Figura 5). Asimismo, el análisis iconográfico de las tabletas permite visualizar una clara diferenciación con aquellas de mango planiforme y decoración incisa lineal característica de la influencia Tiwanaku en San Pedro de Atacama, ya que las tabletas de Caspana se caracterizan por poseer el mango tallado en volumen y por un alto porcentaje de representaciones antropo, zoo y antropo-zoomorfas Tiwanaku (Hermosilla y Alliende 1994 Ms). Entre los animales más representados están el cóndor y el felino, los que junto a las tabletas con dos, tres y cuatro personajes tallados, así como las tabletas con formas tridimensionales de armadillos o roedores remi- ten a las influencias trasandinas. Lo anterior, en su conjunto, nos ha llevado a plantear un sólido vínculo con las poblaciones de dicho territorio, por lo menos desde inicios del Intermedio Tardío, ${ }^{19}$ seguramente aprovechado con posterioridad por el Inca para la incorporación del desierto de Atacama al Tawantinsuyu.

Sin embargo, otro gran conjunto de materiales se encuentra presente entre las ofrendas del cementerio, a los cuales hemos podido acceder gracias al reordenamiento de la colección del Museo de Caspana que hemos logrado realizar a lo largo de estos años de trabajo. ${ }^{20} \mathrm{Al}$ mismo tiempo, resulta evidente el grado de deterioro de la misma en cuanto mucho material se encuentra en muy malas condiciones de conservación debido al deficiente estado de las bodegas del Museo, perdiéndose varios de los cuerpos y objetos elaborados con materias primas perecibles (cestería, calabaza, madera, etc.), así como por la ausencia de una documentación de las piezas óseas y culturales (pérdida de marcas y etiquetas, falta de los registros de excavación e inventario). Intentando salvar todos estos problemas, en la actualidad contamos con un listado mínimo de las ofrendas que se recuperaron y aún se conservan de las excavaciones de Serracino y Barón, así como su respectiva asociación a tumbas y cuerpos.

Es así como tenemos información proveniente de 18 tumbas $(1,2,3,4,5,6,7,8,10,20,23,26,30$, $34,45,47,60$ y 61 ), la mayoría de ellas producto de las mencionadas excavaciones y descritas por Barón, excepto por la 61 que sería el resultado de los posteriores trabajos de un extranjero y de cuyos resultados nada se sabe. ${ }^{21}$ De acuerdo a nuestras pesquisas, además de alfarería y del complejo alucinógeno, hemos podido identificar textilería

19 De hecho, gran parte del complejo alucinógeno de Caspana remite a la fase Yaye de la secuencia de Tarragó (1989), correspondiente a los primeros momentos del Intermedio Tardío durante los cuales sólo se observan los efectos residuales de la interacción entre San Pedro de Atacama con Tiwanaku (950 DC).

20 En este sentido, la tesis de Barón (1979) ha sido un documento de incalculable valor para realizar esta tarea, así como el hecho que casi la totalidad de los objetos recuperados hayan sido marcados.

21 Al parecer se trataría de Bill Harris, según está escrito en algunas etiquetas. 

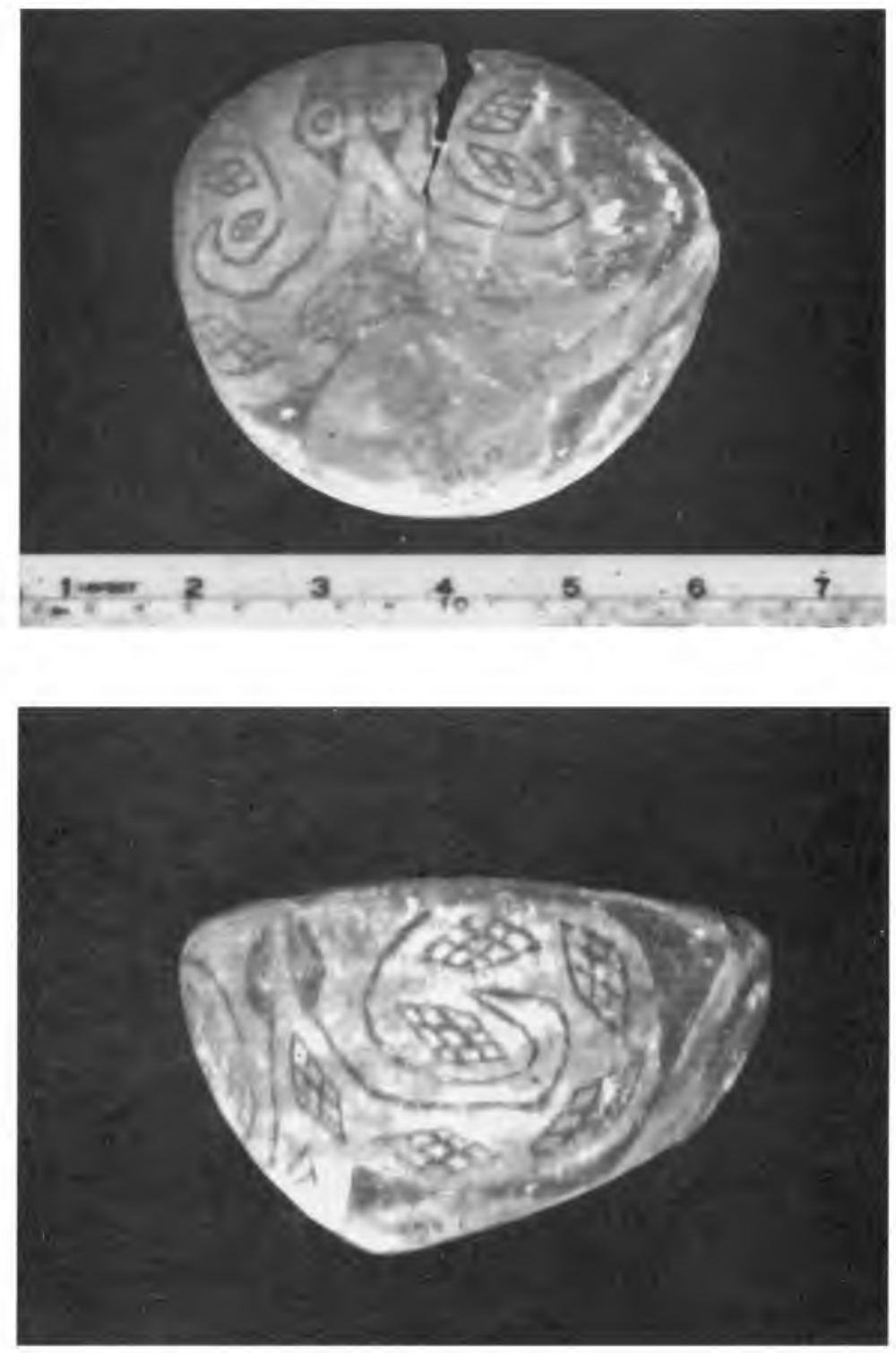

Figura 5. Calabazas pirograbadas

donde se incluyen restos de vestimenta, bolsas, lana, cordelería e instrumentos para tejer como torteras y husos completos de distintos tamaños y formas. También está presente la cestería en forma de platos, fuentes y pucos; el cuero en el caso de bolsas; las calabazas, varias de ellas pirograbadas; herramientas agrícolas como los cuchillones de madera-tejne, las palas de este mismo material y líticas (con mango de madera); vasos-kero, una cuchara, peinetas, ganchos de atala- je y un cencerro entre otros artefactos de madera (Figura 6); las armas aparecen representadas por arcos, astiles e incluso un hacha o martillo de piedra; se encuentran un mortero y otras piedras pulidas de distintos tamaños; cuentas de collares de malaquita, turquesa y vidrio, minerales y pigmentos, así como entre los metales se hallan prendedores-tupus, alfileres, adornos de un gorro "tipo fez", un cincel, anillos, pendientes, botones, campanillas, una cruz cristiana, una moneda y un 


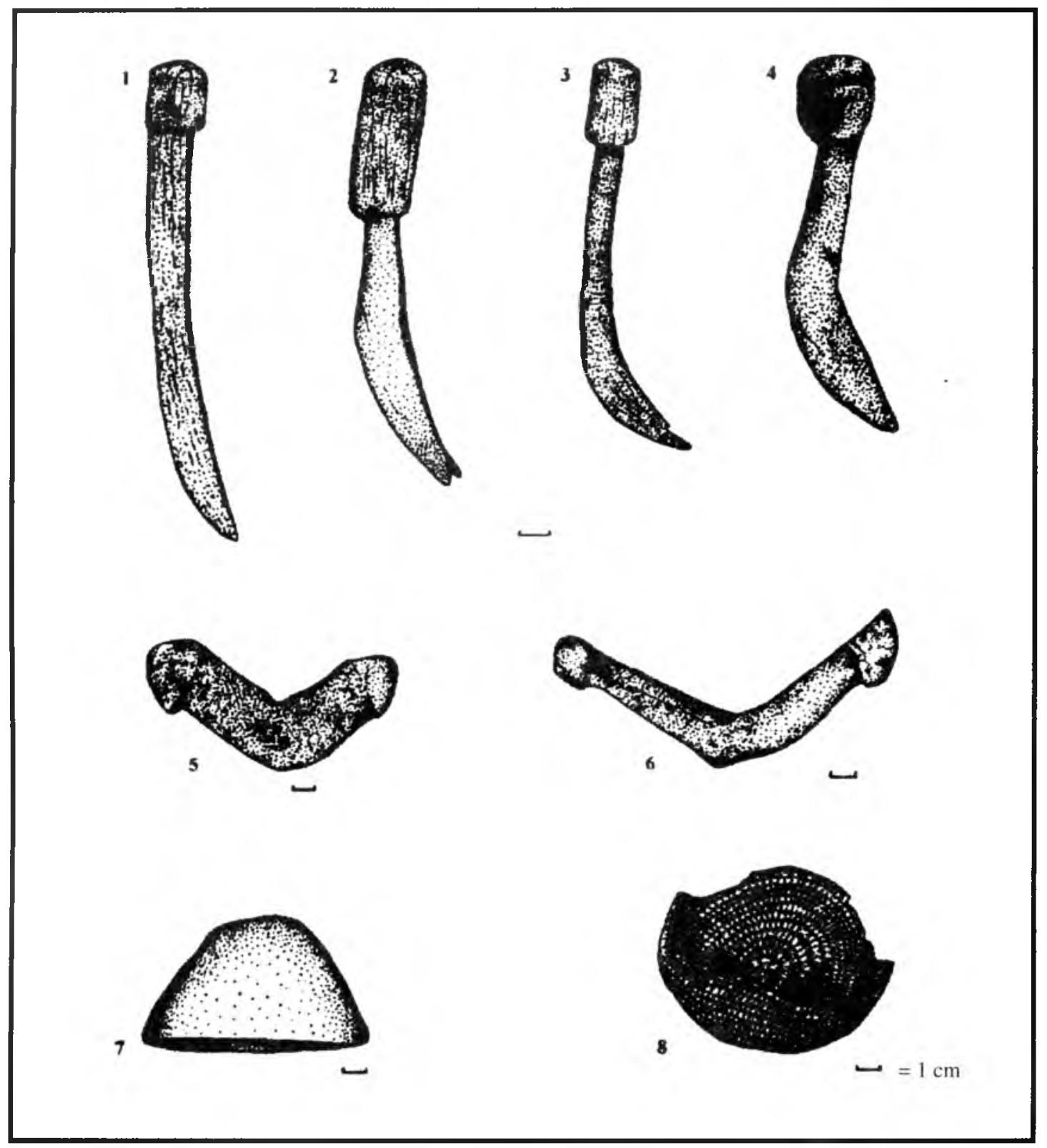

Figura 6. Artefactos de madera y cestería

1 a 4.- Cuchillones de madera o tejne

5 y 6.- Ganchos de atalaje

7.- Cencerro de madera

8.- Recipiente de cestería 


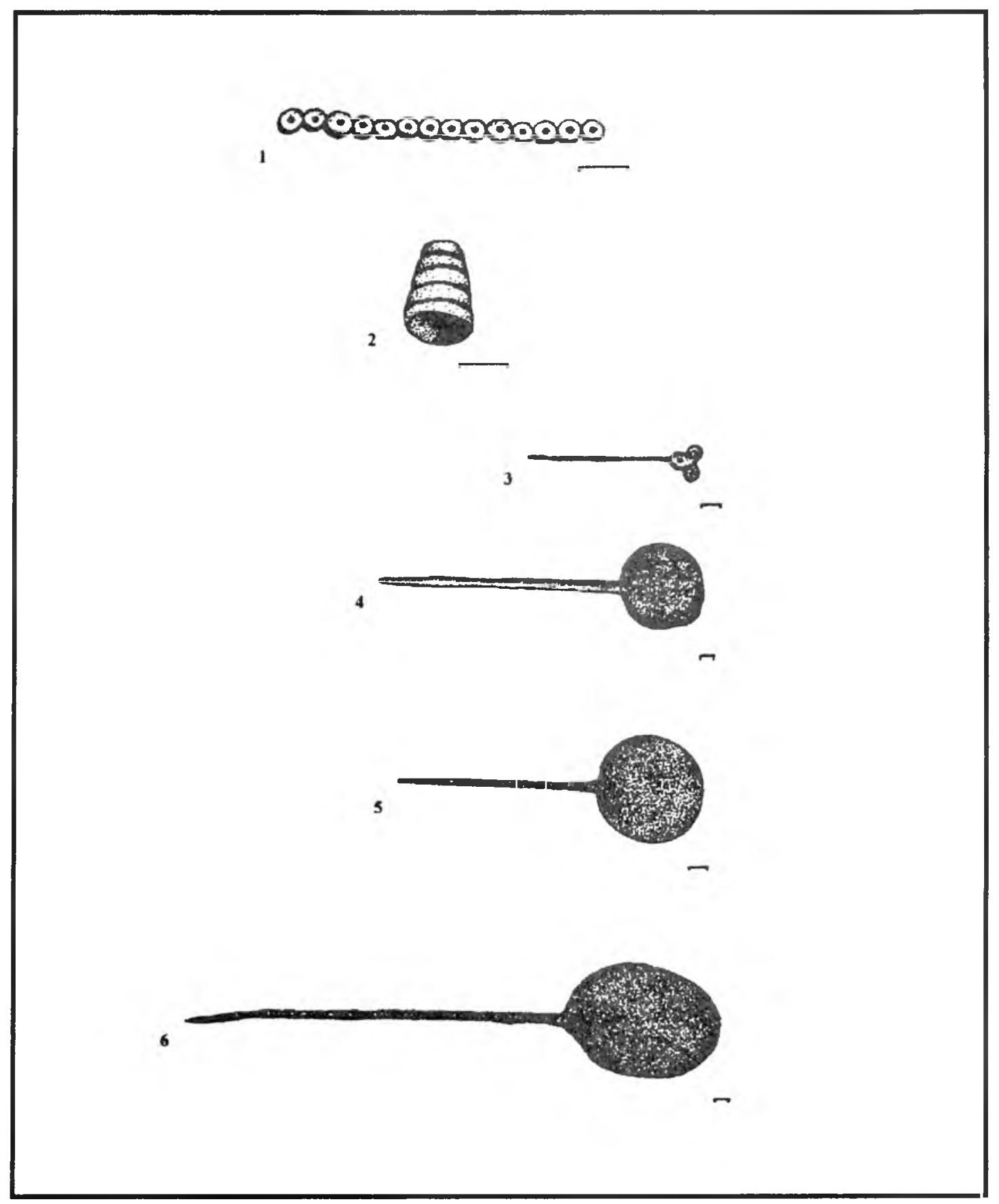

Figura 7. Metalurgia incaica y minerales

1.- Cuentas de malaquita

2.- Campanilla

3.- Alfiler

4 a 6.- Prendedores o tupu 
punzón (Figura 7). A ellos se agregan las evidencias de vegetales donde destacan el maíz, algarrobo y chañar, también aparecen hojas, posiblemente de coca, así como restos de animales (roedores) y comida. Por otra parte, no se puede dejar de notar que el complejo alucinógeno se encuentra representado en todo su conjunto artefactual.

Si bien sabemos que las tumbas son colectivas, por el momento es difícil llevar a cabo un análisis de la asociación entre individuos y ofrendas debido al mal estado de documentación y conservación de la colección. No obstante, estamos en condiciones de caracterizar las tumbas en términos de los materiales que aparecen en ellas y la frecuencia que alcanzan en las mismas. De este modo, tenemos que aparecen entre 0 y 29 clases de ofrendas en las sepulturas, con un promedio de 11,66 objetos por cada una aunque con una desviación estándar de 8,56. Lo anterior se traduce en que el $39 \%$ exhibe una cantidad de ofrendas que varía entre bajo, alto o muy alto, en tanto el $61 \%$ tiene un número muy bajo o mediano. ${ }^{22}$ En este sentido, es posible pensar que los individuos con una proporción moderada de ofrendas, así como aquellos con muy pocas de ellas responden a la conducta funeraria más común y con ello estarían representando al promedio de la población en términos de status y prestigio económico, social y político. En cambio, aquellos con una gran capacidad acumulativa de estos bienes serían muy pocos y se concentrarían en algunas tumbas, otorgándoles un carácter más exclusivo como restringido. En todo caso, las estructuras con casi nulas ofrendas tampoco serían lo más corriente del comportamiento funerario de este cementerio.

Por consiguiente, es interesante observar que la recurrencia de los objetos depositados da cuenta de un predominio en general de los artefactos de madera junto con las calabazas, a los cuales luego se unen la cestería, los cuchillones de madera, los astiles y el maíz, después aparecen los arcos, las palas, los husos y el textil, en tercer lugar se encuentran la alfarería, las calabazas pirograbadas, los ganchos de atalaje y el algarrobo, además de la cordelería y otros restos vegetales. No obstante, el predominio de estas ofrendas es relativo por cuanto la máxima representación individual alcanzada por ellos a penas supera el $5,0 \%$ de frecuencia de los 210 casos registrados para las 58 clases de ofrendas. Con todo, gracias a su amplia dispersión en el cementerio constituirían los objetos más típicos depositados en las tumbas, mientras que el resto serían bienes de un carácter mucho más "exótico", puesto que con dificultad superan el $1 \%$ de presencia en las mismas. Entre ellos destacan los minerales, metales y el complejo alucinógeno, aparte de otros artefactos de madera entre los que destacamos los vasos-kero, una cuchara, peines y un cencerro, un hacha o martillo de piedra, pigmentos, posibles hojas de coca, restos de animales y comida (chañar). En suma, del mismo modo que la cantidad de ofrendas depositadas en las estructuras funerarias del cementerio, la variedad de los objetos da cuenta de importantes diferencias al interior del sitio, distinguiéndose que un reducido grupo de tumbas incluye ofrendas tanto comunes como exclusivas. Dentro de ellas, al mismo tiempo, se pueden segregar preliminarmente aquellas donde destaca el complejo alucinógeno de otras que exhiben metales y minerales, y a su vez, dentro de éstas las que tienen materiales prehispánicos tardíos de las indígena-coloniales.

Considerando estas diferencias es que los datos fueron sometidos a un análisis de agrupamiento de ligamento completo, intentando medir estadísticamente la distancia o diferencias entre las tumbas y sus ofrendas establecidas preliminarmente. En términos generales se generó un sólo dendrograma que se divide en dos grandes ramas con casi un $60 \%$ de distanciamiento entre ellas, situación que interpretamos como la expresión de una sólida tradición cultural (funeraria) que manifiesta un importante cambio o quiebre en cierto momento de su desarrollo. La primera rama incluye una sola tumba (rama única), mientras que la otra comprende a todo el resto (rama principal) que genera dos grupos con menos del 50\% distancia entre ellos. El primero implica apenas dos tumbas, mientras que el segundo aunque se divide cerca del $40 \%$, congrega a todo el resto $(n=15)$, las que se caracterizan por presentar a lo más un $10 \%$ de diferencias entre ellas. Una revisión de1 contenido de las sepulturas confirma nuestras primeras apreciaciones, por cuanto la mayoría corresponde a estructuras donde predominan las ofrendas comunes, mientras que sólo cuatro tum-

22 El número máximo de ofrendas ( $\mathrm{n}=29)$ se dividió en 5 rangos de frecuencia (muy bajo. bajo, mediano, alto y muy alto). 
bas del primer grupo y del segundo de la rama principal, combinan elementos más exclusivos como el complejo alucinógeno, minerales y metales. Así, se constituyen las agrupaciones de esta rama, a los que se uniría el de la rama única, excepto por el hecho de concentrar los materiales indígena-coloniales y por ello el quiebre que se produce.

De este análisis destacamos aquellas estructuras funerarias con claras ofrendas incaicas ${ }_{, 2}^{23}$ reconocidas por su cerámica, puesto que se produce una clara diferenciación de éstas al interior del dendrograma. En primer lugar se encuentra la Tumba $\mathrm{N}^{\circ} 60$, correspondiente a la rama única y donde además se incluyen los materiales indígena-coloniales. Por su parte, de la rama principal se considera el primer grupo formado por las tumbas $\mathrm{N}^{\circ} 7$ y $\mathrm{N}^{\circ} 61$ que señalan cerca de un $20 \%$ de diferencias con el resto. En este sentido, podemos detallar con mayor precisión las características de la conducta funeraria en Caspana, por lo menos en lo que respecta a objetos depositados, durante el dominio del Tawantinsuyu. En la Tumba $\mathrm{N}^{\circ} 7$, aparte de maderas en general, se registró la presencia de calabazas, cestería, maíz, astiles, cuchillones de madera, arcos, torteras, restos de textilería, cerámica tardía (p.e. local, inca-local y Yavi-La Paya), algarrobo, cordelería, peines, espátulas de hueso y madera, agujas de cactus, restos de comida, chañar, un prendedor y un anilllo posiblemente de plata, un vaso de madera, alfiler de cobre, collar de turquesa y un mortero. La Tumba $\mathrm{N}^{\circ} 61$ comparte más del $60 \%$ de estas ofrendas, excepto por el hecho que no se encontraron tejnes, algarrobo, restos de comida, tupus, anillos ni alfileres de metal, tampoco collar de turquesa u otros artefactos de piedra. No obstante, aparecen ganchos de atalaje, algunos restos vegetales indeterminables y también de animales, pendientes de metal, minerales y cuero. Por su parte, algo semejante ocurre con la Tumba $\mathrm{N}^{\circ} 60$ que si bien exhibe la mayor variedad de ofrendas, no presenta maíz, astiles ni arcos, tampoco espátulas de hueso, madera ni agujas de cactus, chañar, alfileres, collar de turquesa ni otras piedras. En este sentido se parece bastante a la Tumba $\mathrm{N}^{\circ} 61$ con la que además comparte los restos de animal, metales indeterminados y cuero. Sin embargo, casi exclusivo de la Tumba $\mathrm{N}^{\circ} 60$ serían las calabazas pirograbadas, collares de malaquita, pigmentos, punzones, metales hispánicos (moneda, cruz, collar), cuchara y pala de madera, y lana.

En definitiva, en todas las tumbas es recurrente la presencia de objetos elaborados en materias primas vegetales como la madera, la calabaza y la cestería, asimismo aparecen la textilería y cordelería tal como ocurre en la mayoría de las estructuras del cementerio. Sin embargo, es clara en aquellas del Período Tardío la concentración de minerales (p.e. los collares de malaquita y turquesa), y metales entre los que destacamos los de filiación incaica como los tupus, al mismo tiempo que ciertos artefactos de madera (p.e. vasos-kero), algunas calabazas pirograbas y la alfarería de estilo Yavi-La Paya en todas presente, además de la cerámica inca-local y otras de origen indeterminable. Asimismo, es evidente en ellas la total ausencia de los componentes principales del complejo alucinógeno (tabletas y tubos), si bien aparecen las espátulas y las agujas de cactus. Por lo tanto, de acuerdo al razonamiento elaborado hasta ahora, esta clase de bienes exclusivos no formarían parte de las ofrendas tardías, específicamente incas, las que más bien mostrarían una tendencia o énfasis por los minerales y metales.

En este sentido, también se propone una microsecuencia para el Período Tardío donde la Tumba $\mathrm{N}^{\circ} 7$ representaría los momentos más tempranos de la expansión del Tawantinsuyu en la localidad, debido a que exhibe la mayor representación de elementos del complejo alucinógeno (espátulas y agujas), menos cerámica "pasta con mica" y una gran concentración del tipo Yavi-La Paya. En tanto las tumbas $\mathrm{N}^{\circ} 61$ y $\mathrm{N}^{\circ} 60$ representarían los momentos más clásicos y tardíos de dicho dominio, puesto que en la práctica ha desaparecido el complejo alucinógeno, en los ejemplares inca-locales predomina la pasta con mica, los que al mismo tiempo son mucho más abundantes que antes y superan a la cerámica Yavi-La Paya, aumenta la

23 La Tumba $N^{\circ} 34$ también presenta cerámica tardía (Saxamar), pero muy fragmentada y con asociaciones confusas. No se describe en la tesis de Barón, por lo que se excluyó de este análisis. La información arquitectónica que se tiene para esta tumbas es muy escasa ya que es una de las sepulturas más reconstruidas del sitio (Ayala 1998 Ms). 
metalurgia y, por último, aparecen objetos hispánicos, en especial cristianos, dentro de los cuales también destaca el metal.

\section{Conclusiones}

Para finalizar quisiéramos compartir, brevemente, algunos datos que nos parecen muy sugerentes para entender el dominio Inca en las quebradas altas del Loa Superior.

En el Cementerio de los Abuelos de Caspana las tumbas asignables a su presencia son escasas dentro de un estilo funerario propio dominante, muy ligado a través de la arquitectura a previas influencias altiplánicas en el Loa Superior. Además, las tumbas con atributos incaicos se ubican bordeando el espacio mortuorio de la población local y en ningún caso se ocupa el núcleo de éste, es decir, donde se concentra la mayor cantidad de sepulturas. Tal situación ocurriría, de acuerdo a las connotaciones temporales de la alfarería así como por el modo de construcción de las tumbas, en momentos tempranos como tardíos de la expansión del Tawantinsuyu y de la incorporación de la localidad al imperio. En definitiva, los incas si bien ocupan el mismo espacio mortuorio de la población local, lo hacen desde su periferia y manteniendo cierta distancia, pero al mismo tiempo, rodeándolo y quizá controlándolo. Lo anterior, nos confirma que la estrategia de dominación incaica es sutil, más política que bélica, pero también efectiva (Gallardo et al. 1995). Por esta razón, algunas estructuras del sector central del cementerio manifestarían cambios arquitectónicos al ser revestidos con cierto "carácter incaico", mostrando la eficacia del poder del Inca, en un momento de completa introducción de la población local al Tawantinsuyu.
Sin embargo, aquellos individuos sepultados que se rodearon de parafernalia incaica ocuparon espacios físicos distintos, marcando una diferencia social, incluso rememorando ciertos cultos típicos del imperio como el de las pacarinas, pero sobretodo incorporando en sus ofrendas mineral y metal quizás como bienes de prestigio, del mismo modo que cerámica que copia el estilo cusqueño y otras piezas foráneas del noroeste argentino. Además de dejar de usar otros materiales como el "complejo del rapé" tan típico entre las ofrendas atacameñas. En este sentido, se trató de personajes especiales, pero sin diferencias biológicas como para pensar que era gente muy distinta a la depositada en el resto del cementerio. El estilo de vida de hombres y mujeres "incanizados" casi no difería de la dura aunque larga existencia de los antiguos caspaneños, excepto porque pudieron haber tenido una dieta relativamente mejor, según lo sugiere la mayor estatura de un par de aquellos.

Pareciera que es la población local, o mejor dicho parte de ella, la encargada de reproducir el sistema. Lo anterior no es de extrañar, si se considera que tiende a expresarse una relación, aún no absoluta, entre ofrendas incaicas, especialmente cerámica, y mujeres, como si el Inca las hubiera utilizado a ellas para reafirmar su dominio en las unidades domésticas a través de los lazos de parentesco. Sin duda, faltan muchas evidencias para afirmar con toda propiedad lo último, pero sería una de las prácticas esperadas de su estrategia, tal cual lo sugieren también algunos contextos funerarios de San Pedro de Atacama (Tarragó 1989). En consecuencia, el Tawantinsuyu en esta parte de los Andes se construiría, a nuestro juicio, a partir de los vínculos contraídos entre las poblaciones del desierto de Atacama y el Noroeste argentino con el Cusco. 


\section{BIBLIOGRAFIA}

ALDUNATE, C. Arqueología del Pukara de Turi. Ac1993 tas del XII Congreso de Arqueología Chilena, Boletín del Museo Regional de la Araucanía, Tomo II (4):61-78, Temuco.

ALDUNATE, C. y V. CASTRO. Las chullpas de Toconce y 1981 su relación con el poblamiento altiplánico en el Loa Superior. Período Tardío. Tesis para optar al grado de Licenciado en Filosofía con mención en Prehistoria y Arqueología. Facultad de Filosofía, Humanidades y Educación, Universidad de Chile, Santiago.

ALLIENDE, P. La colección arqueológica "Emil de 1981 Bruyne" de Caspana. Tesis para optar al grado de Licenciado en Filosofía con mención en Prehistoria y Arqueología. Facultad de Filosofía, Humanidades y Educación, Universidad de Chile, Santiago.

AYALA, P. Arquitectura para los muertos, el Ce$1998 \mathrm{Ms}$ menterio de los Abuelos de Caspana, Informe Proyecto FONDECYT 1980528, Santiago.

1999 Cementerio de los abuelos de Caspana: Una forma de hacer arqueología o un problema de ética arqueológica. Boletín de la Sociedad Chilena de Arqueología 27:28-32, Santiago.

$2000 \quad$ Reevaluación de las tradiciones culturales del Período Intermedio Tardío en el Loa Superior: Caspana. Memoria para optar al Título de Arqueóloga. Departamento de Antropología, Facultad de Ciencias Sociales, Universidad de Chile, Santiago.

2000 a Apropiación y transformación de arquitectura altiplánica en el Loa Superior: La aldea de Talikuna. Actas del XIV Congreso de Arqueología Chilena pp. 793-813, Copiapó.

AUFDERHEIDE, A., y C. RODRIGUEZ-MARTIN. Encyclo1998 pedia of human paleopathology, Cambridge University Press, New York.

BARON, A.M. Excavación de un cementerio: Sus po1979 tencialidades. Tesis para optar al grado de Licenciada en Prehistoria y Arqueología, Universidad de Chile, Santiago.

BROOKS, S., R. BROOKS y D. FRANCE. Alveolar progna1990 thism contour, an aspect of racial identification. Skeletal attribution of
Race. Methods for Forensic Antrophology, pp. 41-46, W. G. Gill y S. Rhine (Eds.), University of New Mexico, Albuquerque.

BROTHWELL, D.R. Desenterrando huesos. La excava1987 ción, tratamiento y estudio de restos del esqueleto humano. Fondo de $\mathrm{Cul}$ tura Económica, México.

CASTRO, V., C. ALDUNATE y J. BERENGUER. Orígenes 1984 altiplánicos de la Fase Toconce. Estudios Atacameños, 7:209-235, San Pedro de Atacama.

CASTRO, V., F. MALDONADO y M. VASQUEZ. Arquitec1993 tura del Pukara de Turi. Actas del XII Congreso de Arqueología Chilena, Tomo II (4):79-106, Museo Regional de la Araucanía, Temuco.

COSTA-JUNQUEIRA, M.A., y A. LLAGOSTERA. Coyo-3: 1994 Momentos finales del período medio en San Pedro de Atacama. Estudios Atacameños 11:73-107, San Pedro de Atacama.

EATON, G. La colección del material osteológico 1990[1919] de Machu Picchu. Sociedad de Arqueología Andina, Lima.

GALLARDO, F., M. URIBE y P. AYALA. Arquitectura inca y 1995 poder en el Pukara de Turi (Norte de Chile). Gaceta Arqueológica Andina (VII) 24:151-172, Lima.

GILBERT, R. y G. GILL. A metric technique for identifying 1990 american indian femora. Skeletal attribution of Race. Methods for Forensic Antrophology, pp. 97-99, W.G. Gill y S. Rhine (Eds.), University of New Mexico, Albuquerque.

HERMOSILLA, N., y P. ALLIENDE. La parafernalia in1994 Ms suflatoria de Caspana de la colección Emyl de Bruyne. Informe Proyecto FONDECYT 1940097, Santiago.

HILLSON, S. Dental anthropology. Cambridge Uni1996 versity Press, New York.

KENNEDY, K. Skeletal markers of occupational stress 1989 Reconstruction of life from the skeleton, pp. 129-160, M.Y. Iscan y K. Kennedy (Eds.), Alan R. Liss Inc., New York.

LE PAIGE, G. Antiguas culturas atacameñas en la cor1958 dillera Chilena. Anales de la Universidad Católica de Valparaíso 4-5, Valparaíso. 
LOTH, S.R., y M.Y. I SCAN. Morphological assessment of 1989 age in the adult: the thoracic region. Age markers in the human skeleton, $\mathrm{pp}$. 105-135, M.Y. Iscan (Ed.), Charles Thomas Publisher.

LOVEJOY, C.O., R.S. MEINDL, T.R. PRYZBECK y R.P. 1985 MENSFORTH. Chronological metamorphosis of the auricular surface of the illium: A new method for the determination of adult skeletal age at death American journal of physical anthropology 68:15-28.

MARTI, I., F. ROTHHAMMER, P. MENDOZA y C. SILVA $1994 \quad$ Paleopatología dentaria de poblaciones precolombinas chilenas sometidas a condiciones medioambientales contrastantes. Antropología Bíológica 2:7584, Santiago.

MEINDL, R., y C.O. LOVEJOY. Ectocranial suture closure: 1985 A revised method for the determination of skeletal age at death based on the lateral-anterior sutures. American journal of physical anthropology 68:57-66.

NAPOLI, M., y W. BIRKBY. Racial differences in the visibility 1990 of the oval window in the middle ear. Skeletal attribution of Race. Methods for Forensic Antrophology, pp. 27-33, W.G. Gill y S. Rhine (Eds.), University of New Mexico, Albuquerque.

NIELSEN, A. Tendencias de larga duración en la ocu1998 pación humana del altiplano de Lípez (Potosí, Bolivia). En Los desarrollos locales y sus territorios. Arqueología del NOA y Sur de Bolivia, pp. 65-102, Universidad Nacional de Jujuy, Jujuy.

NUÑEZ, L. Prospección arqueológica en el norte de 1965 Chile. Estudios Arqueológicos 1:9-35 Antofagasta.

ORTNER, D., y W. PUTSCHAR. Identification of patholo1981 gical conditions in human squeletal remains. Smithsonian Institution Press, Washington.

POLLARD, G. The cultural ecology of ceramic stage 1982[1970] settlement in the Atacama Desert, PH. D. Dissertation, Columbia University, University Microfilms Int., Ann Arbor.
QUEVEDO, S., y P. URQUIETA. Abrasión dentaria de un gru1975 po preagrícola de la costa chilena. Antropología Nueva Epoca 2:145-153, Santiago.

REYES, $0 . \quad$ Análisis paleopatológico de la población 2000 prehispánica tardía del cementerio de "Los Abuelos" de Caspana, Loa Superior, desierto de Atacama. Enviado a Chungara, Arica.

SHIPMAN, P., A. WALKER y D. BICHELL. The human ske1985 leton. Harvard University Press.

TARRAGO, M. Contribución al conocimiento arqueo1989 lógico de las poblaciones de los oasis de San Pedro de Atacama en relación con los otros pueblos puneños, en especial, el sector septentrional del valle Calchaquí. Tesis para optar al título de Doctor en Historia, Especialidad Antropología, Universidad Nacional de Rosario, Facultad de Humanidades y Artes, Rosario.

TSCHOPICK, M. H. Some notes on the archeology of the 1946 departament of Puno. Papers of the Peabody Museum of American Archeology and Ethnology 27 (3) Harvard University.

UBELAKER, D. Human skeletal remains. Manuals on 1996 archeology 2, Smithsonian Institution Press, Washington.

URIBE, M. Religión y poder en los Andes de Loa: 1996 Una reflexión desde la alfarería. Tesis para optar al título profesional de Arqueólogo, Universidad de Chile, Santiago.

1997 La alfarería de Caspana y su relación con la prehistoria tardía de la Subárea Circumpuneña. Estudios Atacameños 14:243-262, San Pedro de Atacama.

1999 La alfarería Inca de Caspana (norte de Chile). Boletín de la sociedad Chilena de Arqueología 27:11-18, Santiago.

VARELA, V., M. URIBE y L. ADAN. La cerámica arqueoló1993 gica del sitio 02TU001: Pukara de Turi. Actas del XII Congreso de Arqueología Chilena, Tomo II, 4:107-122, Museo Regional de la Araucanía, Temuco. 